
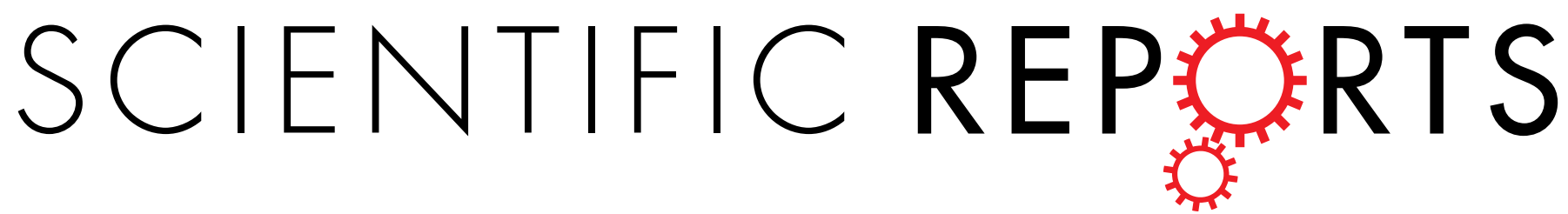

\title{
Critical Role of COI1-Dependent
} Jasmonate Pathway in AAL toxin induced PCD in Tomato Revealed by

Received: 27 April 2016 Accepted: 31 May 2016 Published: 21 June 2016

\section{Comparative Proteomics}

Min Zhang ${ }^{1, *}$, Jin Koh ${ }^{2, *}$, Lihong Liu ${ }^{1,3,{ }^{*}, \text { Zhiyong Shao }}{ }^{1}$, Haoran Liu ${ }^{1}$, Songshen $\mathrm{Hu}^{1}$, Ning Zhu ${ }^{3}$, Craig P. Dufresne ${ }^{4}$, Sixue Chen ${ }^{2,3}$ \& Qiaomei Wang ${ }^{1,5}$

Alternaria alternata f.sp. Lycopersici (AAL) toxin induces programmed cell death (PCD) in susceptible tomato (Solanum lycopersicum) leaves. Jasmonate (JA) promotes AAL toxin induced PCD in a COI1 (coronatine insensitive 1, JA receptor)-dependent manner by enhancement of reactive oxygen species (ROS) production. To further elucidate the underlying mechanisms of this process, we performed a comparative proteomic analysis using tomato jasmonic acid insensitive1 (jai1), the receptor mutant of JA, and its wild type (WT) after AAL toxin treatment with or without JA treatment. A total of 10367 proteins were identified in tomato leaves using isobaric tags for relative and absolute quantitation (iTRAQ) quantitative proteomics approach. 2670 proteins were determined to be differentially expressed in response to AAL toxin and JA. Comparison between AAL toxin treated jai1 and its WT revealed the COI1-dependent JA pathway regulated proteins, including pathways related to redox response, ceramide synthesis, JA, ethylene (ET), salicylic acid (SA) and abscisic acid (ABA) signaling. Autophagy, PCD and DNA damage related proteins were also identified. Our data suggest that COI1dependent JA pathway enhances AAL toxin induced PCD through regulating the redox status of the leaves, other phytohormone pathways and/or important PCD components.

Fungi usually produce toxins to damage plant tissues, which are classified as host-selective or non-specific. Host-selective toxins (HSTs) only infect host plants, but non-specific toxins can infect plants whether they are a host or non-host of fungus producing pathogen ${ }^{1}$. Alternaria alternata f.sp. Lycopersici (AAL) toxin is a kind of HST, it is the main virulence effector produced by AAL, causing stem canker and leaf necrosis on tomato (Solanum lycopersicum) plants of the asc/asc genotype ${ }^{2,3}$, leading to serious crop loss. The recessive allele (asc/asc) is associated with a mutation in the single codominant Alternaria Stem Canker (ASC) gene, which determines the insensitivity of plants to fungal $\mathrm{AAL}^{4}$. AAL toxin is one type of sphinganine analogue mycotoxins (SAMs) that are inhibitors of eukaryotic sphinganine $\mathrm{N}$-acyltransferase (acyl-CoA-dependent ceramide synthase), a key enzyme in the sphingolipid ceramide biosynthetic pathway ${ }^{5}$. The disruption of sphingolipid biosynthesis causes marked elevation of free sphingoid bases such as phytosphingosine and sphinganine ${ }^{6}$, which triggers programmed cell death (PCD) in susceptible plant cells ${ }^{7}$. Among the five series (TA, TB, TC, TD, and TE) of AAL toxin, TA is the most common kind of AAL toxin ${ }^{8}$. As an active and controlled cell death essential for plant defense, PCD functions in diverse biological processes that are related to the complicated network of PCD development ${ }^{9}$. However, the role and regulatory mechanisms of PCD in plants are still poorly understood.

During host-pathogen interactions, jasmonate (JA) and ethylene (ET) are associated with defense against necrotrophic pathogens, while salicylic acid (SA) plays a major role in activation of defense against biotrophic pathogens ${ }^{10}$. Several studies showed that JA and ET are closely related to AAL toxin induced PCD ${ }^{11}$. During

${ }^{1}$ Key Laboratory of Horticultural Plant Growth, Development and Quality Improvement, Ministry of Agriculture, Department of Horticulture, Zhejiang University, Hangzhou 310058, China. ${ }^{2}$ Proteomics and Mass Spectrometry, Interdisciplinary Center for Biotechnology Research, University of Florida, Gainesville, FL 32610, USA. ${ }^{3}$ Department of Biology, Genetics Institute, University of Florida, Gainesville, FL 32610, USA. ${ }^{4}$ Thermo Fisher Scientific, West Palm Beach, Florida 33407, USA. ${ }^{5}$ Zhejiang Provincial Key Laboratory of Horticultural Plant Integrative Biology, Department of Horticulture, Zhejiang University, Hangzhou 310058, China. *These authors contributed equally to this work. Correspondence and requests for materials should be addressed to Q.W. (email: qmwang@zju.edu.cn) 
A
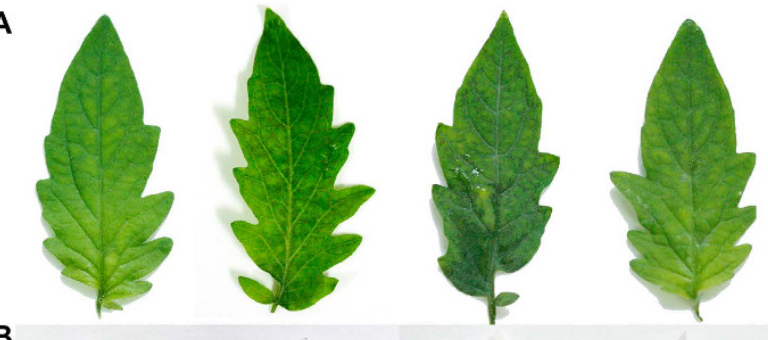

B
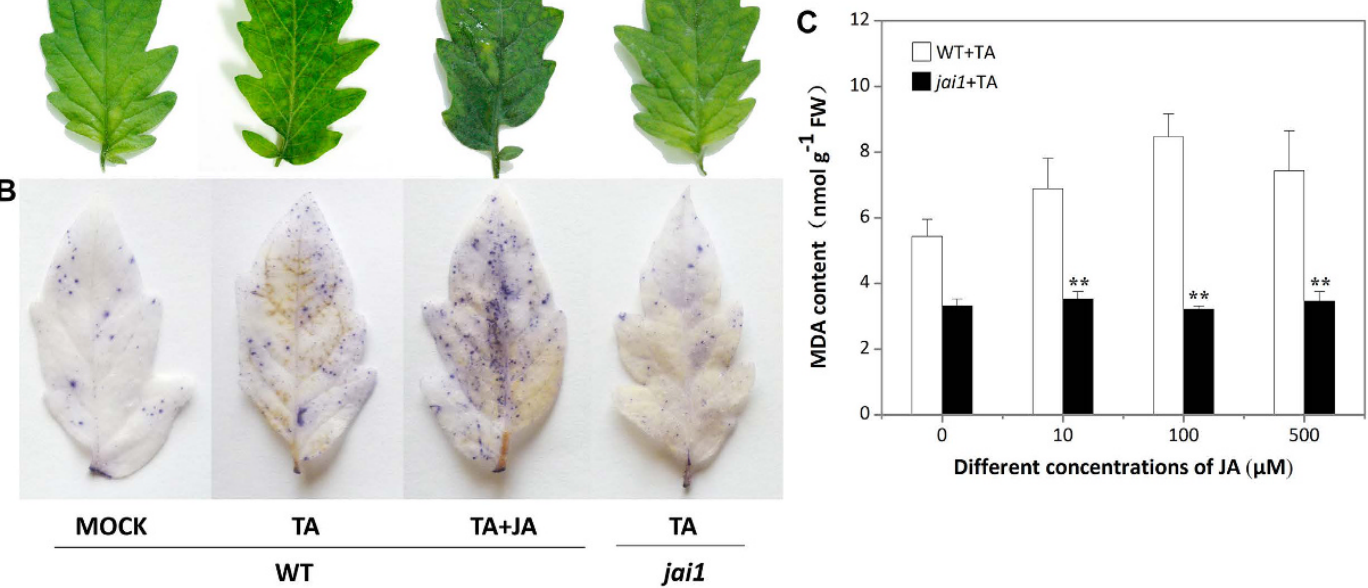

Figure 1. Effect of JA pathway on TA induced PCD in detached tomato leaves. Detached leaflets were incubated under continuous light at $25^{\circ} \mathrm{C}$ for $48 \mathrm{~h}$. WT, wild type; jai1, JA receptor mutant; Mock, WT leaves treated with SPB buffer; TA, WT or jail leaves treated with TA; TA + JA, WT or jail leaves treated with TA and JA. (A) Fully expanded leaflets from nodes between fourth to sixth of 7-week-old plants were treated with $0.2 \mu \mathrm{M}$ TA with or without $100 \mu \mathrm{M} \mathrm{JA}$ and photographed after $48 \mathrm{~h}$. (B) Leaves from WT and jail plants were stained with trypan blue for the degree determination of dead and dying cells after treatment for $48 \mathrm{~h}$. (C) MDA content was detected in WT and jail leaflets after co-treated with different concentrations of JA $(0,10,100$, and $500 \mu \mathrm{M})$ and $0.2 \mu \mathrm{M}$ TA for $48 \mathrm{~h}$. Each data point represents the mean of three replicates. Error bars indicate standard deviation of three replicates, asterisks above the bars indicate statistically significant differences between different treatments, as determined by the Student $t$-tests $(* * \mathrm{P}<0.01)$.

AAL toxin induced PCD process in Arabidopsis loh2 mutant (a T-DNA knockout mutant of a homologue of the tomato $A s c$ gene), ET-responsive genes were up-regulated within seven hours, but JA pathway related genes were unchanged, and there was no indication of JA accumulation ${ }^{12}$. Egusa et al. ${ }^{13}$ reported that methyl-jasmonic acid (MeJA) has a promotional effect on susceptibility of tomato to AAL, suggesting that pathogen might utilize JA signaling pathway for successful infection. Moreover, our previous study showed that JA and ET promoted AAL toxin induced cell death alone, and the receptor-dependent JA signaling promotes PCD through enhancing ET biosynthesis ${ }^{11}$. jail (jasmonic acid insensitive1) contains a mutation in the tomato homologue of Arabidopsis COI1 and fails to express JA-regulated genes in response to wounding and MeJA ${ }^{14}$. Hence, the system of AAL toxin and its susceptible tomato host is an excellent model for studying PCD in pathogen response pathways, as the PCD process can be evaluated in a system absence of pathogen, which greatly simplifies the analysis. Besides, the jai1 mutant allows us to conduct an extensive study in the role of JA pathway in AAL toxin induced PCD.

Reactive oxygen species (ROS) are well known as toxic metabolic substance that can initiate PCD in plant ${ }^{15}$. In Arabidopsis, the responses of the JA signaling mutants jar 1 and $f a d 3 / 7 / 8$ to $\mathrm{O}_{3}$ have indicated that JA could be an important factor involved in the ROS-dependent lesion propagation ${ }^{16}$, hence it is quite interesting to investigate the relationship between ROS and JA pathway during AAL toxin induced PCD.

Although large scale transcriptome analysis has deepened our understanding of the molecular basis of toxin induced PCD, proteomics is another powerful tool to further reveal the regulatory and metabolic pathways underlying plant development and response to stresses ${ }^{17,18}$. In this study, we investigated whether JA promoted AAL toxin induced PCD in a COI1-dependent way, and ROS acted downstream of JA in this process. In addition, a comparative proteomics analysis was performed on AAL toxin treated jail mutant and its WT. The data revealed that JA pathway promoted AAL toxin induced PCD by regulating the ROS status of the leaves and relevant PCD components and/or through other hormone pathways in a COI1-dependent manner.

\section{Results}

COI1-dependent jasmonate pathway promotes TA induced cell death. The visible necrotic lesions were observed at $36 \mathrm{~h}$ in leaves of WT plants after TA treatment (data not shown), and the lesions became typical at $48 \mathrm{~h}$. The PCD symptom was enhanced dramatically in WT leaves when treated with TA and JA together in comparison with TA treatment alone (Fig. 1A), suggesting that JA can promote TA induced PCD. Neverthless, TA treated jail leaves displayed minor tissue damage at $48 \mathrm{~h}$, and exogenous JA did not exert effect on it, indicating that COI1 is involved in the PCD process triggered by TA and the impaired JA perception in jail inhibited JA promoted PCD.

Trypan blue staining is an accepted method for cell viability assay, live cells or tissues with intact cell membranes are not coloured, and dead cells can be colored in light blue ${ }^{19}$. As can be seen in Fig. 1B, TA treated WT leaves accumulate more blue precipitate compared with the control, and JA enhanced the accumulation of blue 

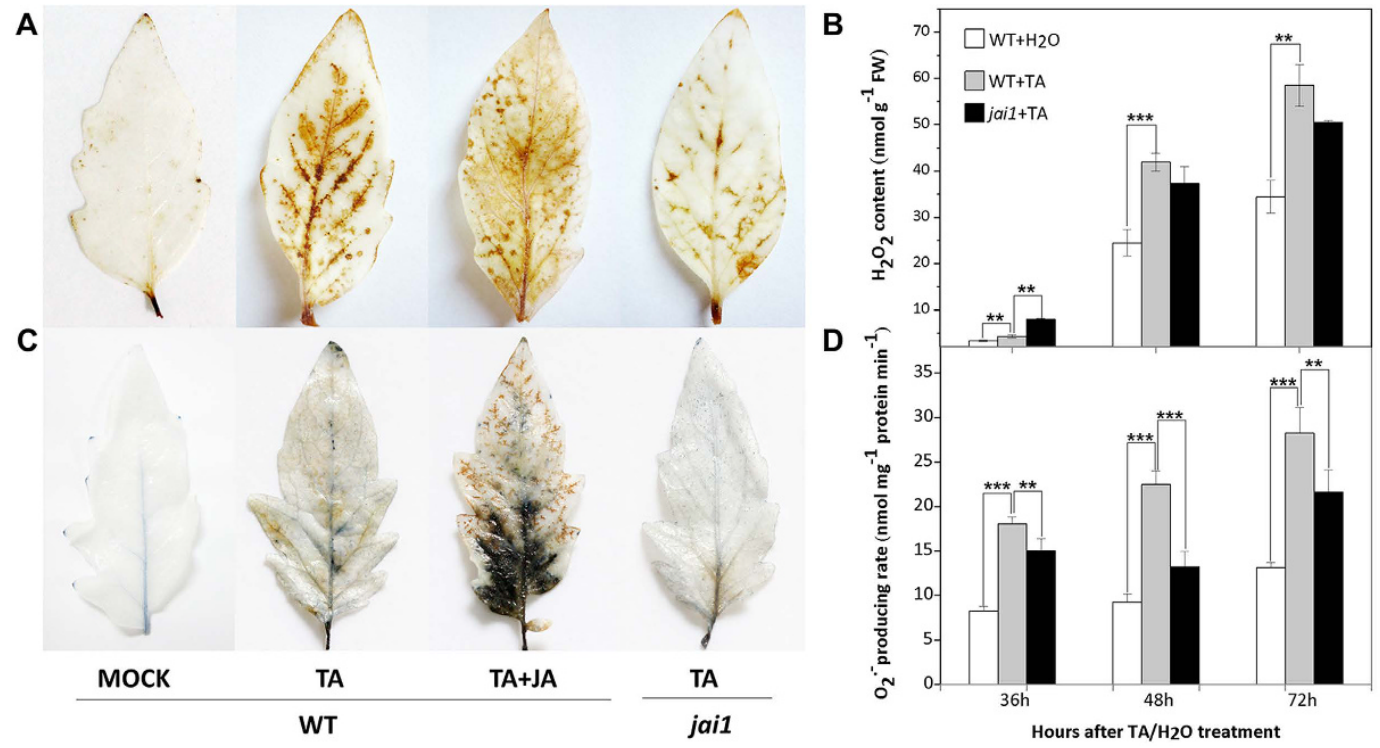

Figure 2. Effect of JA pathway on TA induced ROS accumulation in detached tomato leaves. WT, wild type; jai1, JA receptor mutant; Mock, WT leaves treated with SPB buffer; TA, WT or jail leaves treated with TA; TA + JA, or jail leaves treated with TA and JA. (A) Leaves of WT and jail were stained with DAB for $\mathrm{H}_{2} \mathrm{O}_{2}$ determination at $48 \mathrm{~h}$ after $0.2 \mu \mathrm{M}$ TA treatment with or without $100 \mu \mathrm{M} \mathrm{JA}$. (B) Changes of $\mathrm{H}_{2} \mathrm{O}_{2}$ content in WT and jail leaves after $0.2 \mu \mathrm{M}$ TA treatment for 36, 48 and $72 \mathrm{~h}$. (C) Leaves of WT and jail were stained with $\mathrm{NBT}$ for $\mathrm{O}_{2}{ }^{-{ }^{-}}$determination at $48 \mathrm{~h}$ after $0.2 \mu \mathrm{M}$ TA treatment with or without $100 \mu \mathrm{M} \mathrm{JA}$. (D) Changes of $\mathrm{O}_{2}{ }^{-{ }^{-}}$producing rate in WT and jail leaves after $0.2 \mu \mathrm{M}$ TA treatment for 36, 48 and $72 \mathrm{~h}$. Each data point represents the mean of three replicates. Error bars indicate standard deviation of three replicates, asterisks above the bars indicate statistically significant differences between different treatments, as determined by the Student $t$-tests $(* * \mathrm{P}<0.01, * * * \mathrm{P}<0.001)$.

precipitate, indicating that JA can promote TA induced PCD. Besides, TA treated jail leaves accumulated less blue precipitate compared with TA treated WT leaves, which was consistent with the visible phenotype (Fig. 1A), further proved that JA pathway is important for TA induced PCD.

Malondialdehyde (MDA) is the final product of membrane lipid peroxidation, which can be a marker for oxidative stress ${ }^{20}$. MDA content in TA treated WT leaves increased with the increase in JA concentration, and peaked at $100 \mu \mathrm{M} \mathrm{JA}$. However, no visible change was found in jail leaves with the increase in JA concentration (Fig. 1C), indicating that JA enhanced membrane lipid peroxidation in a COI1-dependent way.

JA enhances ROS accumulation during TA induced PCD. Hydrogen peroxide $\left(\mathrm{H}_{2} \mathrm{O}_{2}\right)$ and superoxide $\left(\mathrm{O}_{2}{ }^{-}\right)$are the two key ROS molecules. We carried out histochemical 3,3'- diaminobenzidine (DAB) ${ }^{21}$ and nitro blue tetrazolium (NBT) staining ${ }^{22}$ to detect $\mathrm{H}_{2} \mathrm{O}_{2}$ and $\mathrm{O}_{2}{ }^{-}$in the leaves, respectively. As shown in Fig. $2 \mathrm{~A}$, after TA treatment for $48 \mathrm{~h}$, large brown precipitation was observed to be around the leaf veins of WT plants by DAB staining, and the brown region was expanded by JA treatment. However, jail leaves showed little precipitation after TA treatment, suggesting less ROS production in jail. The $\mathrm{H}_{2} \mathrm{O}_{2}$ content in WT and jail leaves increased steadily during three days with TA treatment, whereas in jail it was significantly lower than WT leaves, except for $36 \mathrm{~h}$ after treatment (Fig. 2B). Similarly, much more blue precipitates in TA and JA treated WT leaves was observed than in jail leaves by NBT staining (Fig. 2C). $\mathrm{O}_{2}{ }^{-}$production rate in WT and jail leaves both increased constantly in three days after TA treatment, but it was significantly lower in TA treated jail compared with WT leaves at the same time point (Fig. 2D). Based on these results, it is proposed that ROS burst occurs during TA induced PCD, and the impairment of COI1 suppresses the production of ROS, as well as the necrotic cell death. In Fig. 2B,D, $\mathrm{H}_{2} \mathrm{O}_{2}$ content and $\mathrm{O}_{2}{ }^{-}$production rate in the untreated leaves were also increased slightly, possibly caused by the minor stress brought by the treatment.

Proteome profiling of tomato leaves. To better understand the mechanisms in TA response of tomato leaves and how JA influences the process, a comparative proteomic analysis was performed in JA insensitive mutant jail and its WT after TA treatment with or without JA treatment. We employed high-resolution MS in combination with isobaric tags for relative and absolute quantitation (iTRAQ) proteomics approach to identify the proteome changes. In our workflow, there are four biological replicates for each treatment and one set of iTRAQ includes two biological replicates (Fig. 3A). We identified a total of 8501 tomato proteins with $1 \%$ global false discovery rate (FDR) (Supplementary Figure S1) and 10367 tomato proteins with 5\% FDR (Fig. 3B), and the 10367 proteins were chosen for the subsequent analysis.

Functional classification of the $\mathbf{1 0 3 6 7}$ proteins. The identified proteins were analyzed based on the assigned functions of the proteins using Uniprot, NCBI and phytozome databases. The biological process of the overall 10367 proteins were classified into 36 categories sorted by the Blast2Go level 4 (Fig. 3D), among them 
A

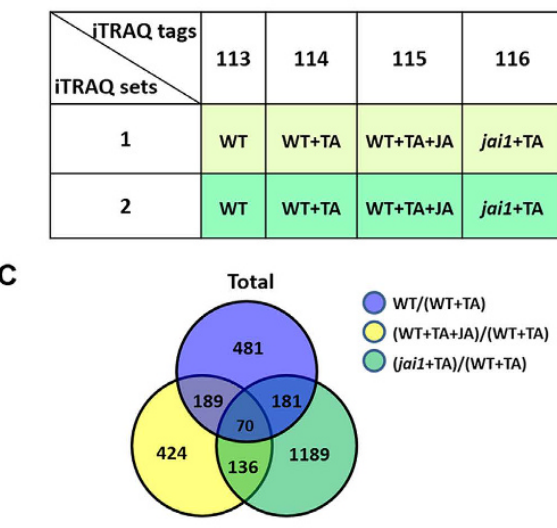

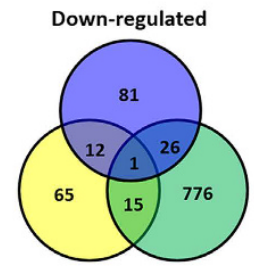

\begin{tabular}{|c|c|c|c|}
\hline 117 & 118 & 119 & 121 \\
\hline WT & WT+TA & WT+TA+JA & jai1+TA \\
\hline WT & WT+TA & WT+TA+JA & jai1+TA \\
\hline
\end{tabular}

B

D

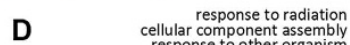
response to radiation
cellular component assembly
response to other organism response to other organism
protein localization cellular developmental process
response to inorganic substance defense response cellular localization
single-organism biosynthetic process single-organism biosynthetic process
lipid metabolic process
ponse to oxygen-containing compound developmental process involved in reproduction response to organic substance
carbohydrate derivative metabolic process ¿

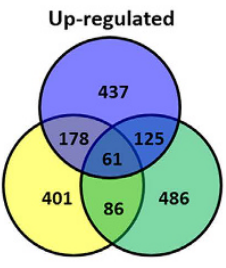

Set 1

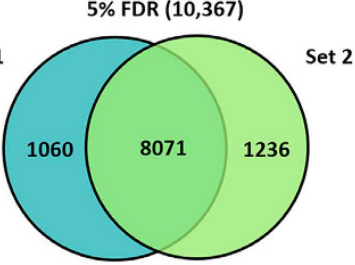

Figure 3. Comparative proteomics identified a large number of proteins involved in TA induced PCD. (A) Label by iTRAQ reagent. WT refers to the wild type leaves as control; WT + TA, WT leaves treated with TA; WT + TA + JA, WT leaves treated with TA and JA together; jai1 + TA, jail leaves treated with TA. Four biological replicates for each treatment and one set of iTRAQ includes two biological replicates. (B) Total protein number identified in two sets with $5 \%$ false discovery rate (FDR), set 1 is colored in blue, set 2 is colored in green. (C) Distribution and overlap of differentially expressed (DE) proteins in each comparison. WT $+\mathrm{TA}$ was set as the control group for the other groups. Each color represents one contrast. Blue, WT vs WT + TA; Yellow, WT + TA + JA vs WT + TA; Green, jai1 + TA vs WT + TA. (D) GO terms distribution of the overall 10367 proteins categorized in "biological process". GO-terms were categorized by Blast2Go at level 4 according to their corresponding GO-term (biological process). Each protein may be identified in more than one process.

most proteins were involved in macromolecule metabolic process (36\%), organic substance biosynthetic process $(28 \%)$ and cellular biosynthetic process (27\%), regulation of cellular process (17\%), oxidation-reduction process (12\%) and cellular response to stimulus (12\%). Interestingly, there were $9 \%$ proteins involved in cell communication, $8 \%$ proteins involved in the lipid metabolic process, $7 \%$ proteins involved in the defense response, other proteins were involved in transport (15\%), organelle organization (12\%), developmental process including reproduction (9\%) and anatomical structure morphogenesis (7\%).

Subcellular localization of the 10367 proteins. The identified proteins were further classified according to their sub-cellular localization (Supplementary Figure S4). As shown in the graph, the proteins were mainly located in nucleus and chloroplast (both 16\%), followed by cytosol, mitochondrion and membrane (above 8\%), cytoplasm (7\%), plasma membrane (6\%), golgi (6\%), vacuole (4\%), ribosome (3\%), cell wall (3\%) and so on, while $7 \%$ had no specified sub-cellular localization. Significantly, the percentage of proteins located in plasmodesma is $2 \%$, this location may indicated the communication between cells.

Functional annotation and KEGG pathway analysis of the 10367 proteins. The Kyoto Encyclopedia of Genes and Genomes (KEGG) is a collection of pathways for understanding high-level functions and utilities of the biological system from genomic and molecular-level information ${ }^{23}$. We conducted KEGG pathway analysis of the identified proteins. The proteins were mapped to a total of 139 maps (pathways with more than 40 sequences were represented in Table 1, the others were represented in Supplementary Table S5). The proteins were annotated in various pathways relevant to the synthesis, metabolism or degradation of nucleotide (12\%), amino acid (22\%), carbohydrate (6\%), lipid (14\%), secondary metabolites (31\%), energy (9\%) and xenobiotics (6\%). Especially, the pathways of the immune system included the T cell receptor signaling pathway and biotin metabolism pathway. In addition, phosphatidylinositol signaling system and glycosylphosphatidylinositol (GPI)-anchor biosynthesis were also identified in our study.

Characteristics of the differentially expressed proteins. There were 2670 differencially expressed (DE) proteins (Supplementary Table S4) out of the 10367 proteins (Supplementary Table S3) between the treatment and control samples. The comparison design is displayed as Fig. 3C, WT treated with TA (WT + TA) is the control group for all treated group including WT group. WT vs WT + TA represented proteome changes in WT upon toxin treatment; JA and TA treated WT $(\mathrm{WT}+\mathrm{TA}+\mathrm{JA})$ vs $\mathrm{WT}+\mathrm{TA}$ represented JA induced proteome 


\begin{tabular}{|c|c|c|}
\hline Classification $^{a}$ & KEGG pathways & Sequence number ${ }^{b}$ \\
\hline \multirow{6}{*}{ Nucleotide } & Purine metabolism & 262 \\
\hline & Pyrimidine metabolism & 93 \\
\hline & Amino sugar and nucleotide sugar metabolism & 93 \\
\hline & Pentose and glucuronate interconversions & 74 \\
\hline & Pentose phosphate pathway & 68 \\
\hline & Phenylalanine metabolism & 147 \\
\hline \multirow{14}{*}{ Amino acid } & Glutathione metabolism & 87 \\
\hline & Arginine and proline metabolism & 77 \\
\hline & Glycine, serine and threonine metabolism & 77 \\
\hline & Cysteine and methionine metabolism & 71 \\
\hline & Tryptophan metabolism & 68 \\
\hline & Valine, leucine and isoleucine degradation & 63 \\
\hline & Aminobenzoate degradation & 58 \\
\hline & Aminoacyl-tRNA biosynthesis & 54 \\
\hline & Tyrosine metabolism & 52 \\
\hline & Alanine, aspartate and glutamate metabolism & 51 \\
\hline & Lysine degradation & 46 \\
\hline & Cyanoamino acid metabolism & 46 \\
\hline & $\beta$-Alanine metabolism & 44 \\
\hline & $\begin{array}{l}\text { Phenylalanine, tyrosine and tryptophan } \\
\text { biosynthesis }\end{array}$ & 40 \\
\hline \multirow{2}{*}{ Carbohydrate } & Starch and sucrose metabolism & 212 \\
\hline & Galactose metabolism & 82 \\
\hline \multirow{8}{*}{ Lipid } & Glycerolipid metabolism & 85 \\
\hline & Phosphatidylinositol signaling system & 70 \\
\hline & Fatty acid degradation & 68 \\
\hline & Inositol phosphate metabolism & 59 \\
\hline & $\alpha$-Linoleic acid metabolism & 54 \\
\hline & Glycerophospholipid metabolism & 48 \\
\hline & Fatty acid biosynthesis & 42 \\
\hline & Biosynthesis of unsaturated fatty acids & 41 \\
\hline \multirow{7}{*}{ Secondary metabolites } & Pyruvate metabolism & 93 \\
\hline & Thiamine metabolism & 80 \\
\hline & Glyoxylate and dicarboxylate metabolism & 73 \\
\hline & Methane metabolism & 71 \\
\hline & Flavonoid biosynthesis & 49 \\
\hline & Porphyrin and chlorophyll metabolism & 45 \\
\hline & Ascorbate and aldarate metabolism & 43 \\
\hline \multirow{6}{*}{ Energy } & Glycolysis/Gluconeogenesis & 118 \\
\hline & Carbon fixation in photosynthetic organisms & 87 \\
\hline & Fructose and mannose metabolism & 64 \\
\hline & Oxidative phosphorylation & 58 \\
\hline & Carbon fixation pathways in prokaryotes & 57 \\
\hline & Citrate cycle (TCA cycle) & 48 \\
\hline \multirow{4}{*}{ Xenobiotics } & Drug metabolism - cytochrome P450 & 70 \\
\hline & $\mathrm{T}$ cell receptor signaling pathway & 66 \\
\hline & Metabolism of xenobiotics by cytochrome P450 & 65 \\
\hline & Drug metabolism - other enzymes & 45 \\
\hline
\end{tabular}

Table 1. The most enriched Kyoto Encyclopaedia of Genes and Genomes (KEGG) pathways. ${ }^{a}$ KEGG pathways were classified by metabolic pathways of different molecules. ${ }^{b}$ Sequence number involved in the corresponding KEGG pathways above 40 were presented.

changes upon TA treatment; jail treated with TA ( jai1 + TA) vs WT + TA showed the COI1-dependent proteome changes during the response of plant to TA. 2400 out of 10367 proteins were excluded from the quantitative analysis because variations were detected within biological replicates within each treatment (Supplementary Figure S2).

Among the DE proteins, there were 921, 819, 1576 proteins in WT vs WT+TA, WT + TA + JA vs WT + TA, and jai1 + TA vs WT + TA, respectively (Fig. 3C). It indicates that the COI1 mutation can give rise to the largest 


\begin{tabular}{|c|c|c|c|c|}
\hline $\begin{array}{l}\text { Related } \\
\text { Pathway }\end{array}$ & Sequence Id $^{a}$ & Protein name & $\begin{array}{l}\text { WT+TA+JA/ } \\
\text { WT+TA }^{b} \\
\text { Average fold } \\
\text { change }^{c}\end{array}$ & $\begin{array}{l}\text { WT+TA+JA/ } \\
\text { WT+TA } \\
p \text {-value }^{d}\end{array}$ \\
\hline \multirow{7}{*}{ Cell death } & Solyc11g022590.1.1_1 & Kunitz-like protease partial & 29.9158 & 0.0007 \\
\hline & Solyc04g080960.2.1_1 & Cysteine proteinase rd19a-like & 2.0656 & 0.0055 \\
\hline & Solyc00g071180.2.1_1 & Cysteine protease inhibitor & 23.6525 & 0.0140 \\
\hline & Solyc03g097270.2.1_1 & Cysteine proteinase inhibitor & 6.6684 & 0.0010 \\
\hline & Solyc12g011140.1.1_1 & Subtilisin-like protease & 4.6594 & 0.0003 \\
\hline & Solyc02g092670.1.1_1 & Subtilisin-like protease-like & 2.5589 & 0.0059 \\
\hline & Solyc08g079900.1.1_1 & Subtilisin-like protease-like & 1.7299 & 0.0001 \\
\hline \multirow{3}{*}{ Cell death } & Solyc08g079870.1.1_1 & Subtilisin-like protease-like & 3.5601 & 0.0059 \\
\hline & Solyc04g076190.1.1_1 & Aspartic proteinase nepenthesin-1-like & 12.9902 & 0.0173 \\
\hline & Solyc01g008620.2.1_1 & 3 - $\beta$-glucan endohydrolase short & 5.4506 & 0.0220 \\
\hline \multirow{2}{*}{ Jasmonate } & Solyc03g116110.2.1_1 & $\alpha \beta$-hydrolases superfamily protein & 6.5446 & 0.0269 \\
\hline & Solyc01g008330.2.1_1 & Biotin carboxylase chloroplastic-like & 4.6059 & 0.0258 \\
\hline Ethylene & Solyc11g013170.1.1_1 & $\begin{array}{l}\text { Probable n-succinyldiaminopimelate } \\
\text { Aminotransferase-like }\end{array}$ & 3.0551 & 0.0392 \\
\hline \multirow{4}{*}{$\begin{array}{l}\text { Abscisic } \\
\text { acid }\end{array}$} & Solyc01g097520.2.1_1 & Annexin d4-like & 1.7482 & 0.0007 \\
\hline & Solyc02g081170.2.1_1 & Plastid-lipid-associated chloroplastic-like & 3.4850 & 0.0124 \\
\hline & Solyc09g082780.2.1_1 & Stem-specific protein TSJT1-like & 7.6080 & 0.0212 \\
\hline & Solyc05g009600.2.1_1 & $\begin{array}{l}\text { PP2A } 65 \text { kda regulatory subunit a beta } \\
\text { isoform-like }\end{array}$ & 1.9054 & 0.0118 \\
\hline \multirow{9}{*}{ Resistance } & Solyc02g082920.2.1_1 & Class II chitinase & 8.8545 & 0.0148 \\
\hline & Solyc10g055810.1.1_1 & Class I chitinase & 0.7325 & 0.0078 \\
\hline & Solyc05g007610.2.1_1 & Late blight resistance identical & 5.9576 & 0.0179 \\
\hline & Solyc01g090430.2.1_1 & $\begin{array}{l}\text { Late blight resistance protein homolog } \\
\text { rla-10-like }\end{array}$ & 2.1669 & 0.0238 \\
\hline & Solyc09g011590.2.1_1 & Probable glutathione s-transferase-like & 2.0707 & 0.0002 \\
\hline & Solyc09g090330.2.1_1 & Harpin binding protein 1 & 2.6641 & 0.0277 \\
\hline & Solyc09g090980.2.1_1 & Pathogenesis-related protein 10 & 14.2910 & 0.0001 \\
\hline & Solyc09g090990.2.1_1 & Pathogenesis-related protein 10 & 83.1215 & 0.0356 \\
\hline & Solyc09g091000.2.1_1 & Pathogenesis-related protein sth-2-like & 0.4453 & 0.0131 \\
\hline \multirow{3}{*}{ DNA repair } & Solyc08g074290.2.1_1 & DNA repair ATPase-related family protein & 1.6077 & 0.0058 \\
\hline & Solyc02g021650.2.1_1 & DNA damage-binding protein 1-like & 3.2392 & 0.0350 \\
\hline & Solyc02g082660.2.1_1 & DNA mismatch repair protein & 8.3748 & 0.0406 \\
\hline
\end{tabular}

Table 2. Interesting and novel proteins changed by JA treatment in the process of TA induced PCD. ${ }^{a}$ Accession numbers from GenBank database or Sol Genomics Network (SGN). ${ }^{b}$ WT + TA + JA/WT + TA) represented JA and TA treated WT vs TA treated WT. ${ }^{c}$ Red color represents that the protein was up-regulated, green color represents that the protein was down-regulated. ${ }^{d} t$-test indicates significant difference in expression of these proteins between WT treated with JA and TA and WT treated with TA alone, with p-value threshold values $(\alpha=0.05)$.

changes to tomato proteome. Interestingly, most DE proteins in WT after TA treatment or TA + JA treatment showed higher number of increasing patterns, while those in jail after TA treatment exhibited similar number of increasing and decreasing patterns compared with WT. The expression patterns of the differentially expressed proteins in each comparison groups were clustered and displayed as a heat map in Supplementary Figure S5. Among the increased proteins, 61 were shared by the three comparisons, whereas only one protein was found 


\begin{tabular}{|c|c|c|c|c|}
\hline $\begin{array}{l}\text { Related } \\
\text { pathway }\end{array}$ & Sequence Id ${ }^{a}$ & Protein name & $\begin{array}{l}\text { jail+TA/ } \\
\text { WT }+ \text { TA }^{b} \\
\text { AVE Fold } \\
\text { Change }^{c}\end{array}$ & $\begin{array}{c}j a i 1+\mathrm{TA} \\
\text { WT+TA } \\
p \text {-value } \\
\end{array}$ \\
\hline \multirow{6}{*}{ Redox } & Solyc04g025650.2.1_1 & Monooxygenase 1 & 0.3778 & 0.0099 \\
\hline & Solyc08g069040.2.1_1 & Peroxidase 51-like & 4.0760 & 0.0333 \\
\hline & Solyc12g056250.1.1_1 & Glutathione s-transferase t1-like & 4.2429 & 0.0226 \\
\hline & Solyc01g007740.2.1_1 & 2-cys peroxiredoxin bas1- chloroplastic-like & 9.1890 & 0.0152 \\
\hline & Solyc07g056500.2.1_1 & Probable glutathione s-transferase & 10.1470 & 0.0024 \\
\hline & Solyc02g086090.2.1_1 & Mannose-6-phosphate isomerase 1-like & 25.8542 & 0.0083 \\
\hline \multirow{3}{*}{$\begin{array}{l}\text { Ceramide } \\
\text { metabolic } \\
\text { process }\end{array}$} & Solyc02g078180.2.1_1 & Uncharacterized loc101209711 & 0.0350 & 0.0001 \\
\hline & Solyc05g013720.2.1_1 & Melibiase family protein & 3.9386 & 0.0001 \\
\hline & Solyc03g098220.2.1_1 & Serine palmitoyltransferase & 1.4553 & 0.0020 \\
\hline \multirow{2}{*}{ Autophagy } & Solyc07g005970.2.1_1 & Autophagy-related protein 11 & 0.4675 & 0.0001 \\
\hline & Solyc09g020110.2.1_1 & Ribonuclease 2-like & 8.4530 & 0.0493 \\
\hline \multirow{3}{*}{ Cell death } & Solyc03g098790.1.1_1 & Kunitz-type protease inhibitor precursor & 2.0055 & 0.0196 \\
\hline & Solyc00g130800.1.1_1 & Peptidase c14 caspase catalytic subunit p20 & 1.6202 & 0.0377 \\
\hline & Solyc09g098150.2.1_1 & Metacaspase type II & 1.3907 & 0.0212 \\
\hline \multirow{2}{*}{$\begin{array}{l}\text { JA } \\
\text { synthesis }\end{array}$} & Solyc07g007870.2.1_1 & 12-oxophytodienoate reductase 3 & 4.3415 & 0.0441 \\
\hline & Solyc11g069800.1.1_1 & Allene oxide synthase & 9.4840 & 0.0030 \\
\hline \multirow{5}{*}{ JA response } & Solyc01g010950.2.1_1 & Dual specificity protein kinase spla-like & 0.4950 & 0.0182 \\
\hline & Solyc05g053170.2.1_1 & Chalcone synthase & 0.6337 & 0.0011 \\
\hline & Solyc05g050590.2.1_1 & Phosphoinositide 4-kinase gamma 4 & 0.4500 & 0.0001 \\
\hline & Solyc04g079720.2.1_1 & $\begin{array}{l}\text { 3-n-debenzoyl-2-deoxytaxol n- } \\
\text { Benzoyltransferase-like }\end{array}$ & 0.3109 & 0.0002 \\
\hline & Solyc02g093790.2.1_1 & Probable carboxylesterase 11-like & 0.1006 & 0.0030 \\
\hline $\begin{array}{l}\text { ET } \\
\text { synthesis }\end{array}$ & Solyc03g116110.2.1_1 & $\begin{array}{l}\text { 1-aminocyclopropane-1-carboxylate oxidase } \\
\text { Homolog 1-like }\end{array}$ & 0.4762 & 0.0189 \\
\hline \multirow{4}{*}{$\begin{array}{l}\text { ET } \\
\text { response }\end{array}$} & Solyc04g009850.2.1_1 & Response regulator 1 & 0.1719 & 0.0051 \\
\hline & Solyc04g051080.1.1_1 & $\begin{array}{l}\text { Ethylene-responsive transcription factor } \\
\text { rap2-7-like }\end{array}$ & 0.3854 & 0.0148 \\
\hline & Solyc10g084340.1.1_1 & $\begin{array}{l}\text { AP2-like ethylene-responsive transcription } \\
\text { factor ail5-like }\end{array}$ & 4.9193 & 0.0292 \\
\hline & Solyc07g018290.2.1_1 & Ein3-binding f-box protein 1-like & 5.4162 & 0.0249 \\
\hline \multirow{5}{*}{$S A$ related } & Solyc12g009560.1.1_1 & Acyl-protein thioesterase 1-like & 5.0404 & 0.0297 \\
\hline & Solyc11g012070.1.1_1 & Shikimate kinase like 1 & 5.4686 & 0.0014 \\
\hline & Solyc02g094420.2.1_1 & $\begin{array}{l}\text { Peptidyl-prolyl cis-trans isomerase } \\
\text { Chloroplastic-like }\end{array}$ & 2.7358 & 0.0206 \\
\hline & Solyc02g086910.2.1_1 & $\begin{array}{l}\text { Cytochrome b6-f complex iron-sulfur } \\
\text { chloroplastic-like }\end{array}$ & 2.3017 & 0.0248 \\
\hline & Solyc12g005630.1.1_1 & $\begin{array}{l}\text { Leucine-rich repeat receptor-like } \\
\text { tyrosine-protein kinase at } 2 \mathrm{~g} 41820 \text {-like }\end{array}$ & 3.4704 & 0.0222 \\
\hline \multirow{4}{*}{$\begin{array}{l}\text { ABA } \\
\text { response }\end{array}$} & Solyc11g017270.1.1_1 & $\begin{array}{l}\text { Cbl-interacting serine threonine-protein kinase } \\
\text { 3-like }\end{array}$ & 14.076 & 0.0038 \\
\hline & Solyc05g009600.2.1_1 & $\begin{array}{l}\text { PP2A } 65 \text { kda regulatory subunit a } \beta \\
\text { isoform-like }\end{array}$ & 2.3164 & 0.0206 \\
\hline & Solyc09g082780.2.1_1 & Stem-specific protein tsjt1-like & 7.5958 & 0.0002 \\
\hline & Solyc10g055800.1.1_1 & Class I chitinase & 4.2751 & 0.0024 \\
\hline \multirow{3}{*}{$\begin{array}{l}\text { Receptor } \\
\text { like Kinase }\end{array}$} & Solyc02g014320.1.1_1 & $\begin{array}{l}\text { Probable receptor-like protein kinase } \\
\text { at5g47070-like }\end{array}$ & 0.4852 & 0.0045 \\
\hline & Solyc07g066550.2.1_1 & $\begin{array}{l}\text { Probable LRR receptor-like serine } \\
\text { threonine-protein kinase at1g56130-like }\end{array}$ & 3.0263 & 0.0001 \\
\hline & Solyc03g019980.1.1_1 & $\begin{array}{l}\text { Probable LRR receptor-like serine } \\
\text { threonine-protein kinase at3g47570-like }\end{array}$ & 2.1233 & 0.0012 \\
\hline
\end{tabular}

Table 3. COI1-dependent pathways in response to TA. ${ }^{a}$ Accession numbers from GenBank database or Sol Genomics Network (SGN). ${ }^{b}$ (jail + TA/WT + TA) represented jail treated with TA vs WT treated with TA. ${ }^{c}$ Red color represents that the protein was up-regulated, green color represents that the protein was downregulated. ${ }^{d} t$-test indicates significant difference in expression of these proteins between jail treated with TA and WT treated with TA, with $p$-value threshold values $(\alpha=0.05)$. 
to be decreased in all the comparisons (Fig. 3C), each comparison group also contained their own DE proteins. These proteins present a global view of WT and jail proteome level responses to TA and JA treatment. The expression patterns across each contrasts were classified into 24 categories, as was shown in Supplementary Table S1.

The biological process classification of the 10367 proteins was used as the reference for the functional analysis of DE proteins. We have presented the comparison of functional classification between the 10367 overall detected and 2670 differentially expressed proteins in Supplementary Figure S3, and we found that the biological function processes of the $2670 \mathrm{DE}$ proteins distributed similarly with the overall identified proteins.

JA-regulated proteins in TA induced PCD process. As shown by the previous physiological results that JA promoted PCD, we further investigated JA-regulated proteins in TA induced PCD process, by checking the DE proteins in WT + TA + JA vs WT + TA comparison. The DE proteins related to cell death, JA, ET, ABA, DNA repair and resistance were listed in Table 2. In animal systems, cysteinyl aspartate-specific proteinases (caspases), serine proteases and specific protease inhibitors play crucial roles during the regulation of PCD process ${ }^{24}$. We found that several proteases were increased by JA treatment, including a kunitz-like protease partial, a cysteine proteinase RD19a-like, an aspartic proteinase nepenthesin-1-like and a $\beta$-1, 3-glucanase. Previous study showed that some caspase-like activities are attributable to plant subtilisin-like proteases (SBTs), which are related to cell death ${ }^{25}$. We detected four SBT or SBT like proteins in tomato leaves which were increased by JA treatment. Furthermore, cysteine protease inhibitor (CPI) is known as one of the specific inhibitors of PCD in plant cells ${ }^{26}$. In our experiment, CPI was increased by 23 fold in the WT leaves after treatment with JA and TA together, while increased by two fold after singly TA treatment. These results indicated that TA treatment also induces the expression of some PCD supressors, which could be enhanced by JA treatment. In addition, two JA response proteins, $\alpha \beta$-hydrolases superfamily protein and biotin carboxylase chloroplastic-like, were found to be involved in TA induced PCD. An ET synthesis related protein, probable N-succinyldiaminopimelate aminotransferase-like, was up-regulated by TA + JA treatment compared with TA treatment alone. Four abscisic acid (ABA) response proteins (annexin D4-like, plastid-lipid-associated chloroplastic-like, stem-specific protein TSJT1-like, and PP2A 65 $\mathrm{kda}$ regulatory subunit $\alpha \beta$ isoform-like) were also increased by JA treatment in response to TA, indicating the possible involvement of ET and ABA pathway in TA induced PCD.

Pathogenesis-related proteins (PRs) are general markers for basal defense response. Two PR10 proteins increased significantly after TA + JA treatment compared with TA treatment alone, while PR-sth2-like protein and PR1 were decreased by JA treatment. Besides, several late blight resistance proteins, a chitinase and a harpin binding protein were also increased by TA + JA treatment, implying that JA could promote the synthesis of resistance proteins. The DNA damage response (DDR) plays an important role against detrimental effects of stress ${ }^{27}$. Three DNA repair related proteins (DNA repair ATPase-related family protein, DNA damage-binding protein 1-like, and DNA mismatch repair protein), were increased by JA during TA induced PCD.

COI1-dependent signaling pathways in response to TA. We were interested in COI1-dependent signaling pathways in response to TA, as previous results have shown that COI1 impairement inhibits TA induced PCD in tomato leaves. DE proteins between TA treated jail and WT were classified as COI1-dependent proteins in response to TA. The candidate proteins related to defense response and programmed cell death were listed in Table 3. Firstly, six reductase proteins (peroxidase 51-like, glutathione s-transferase T1-like, 2-cys peroxiredoxin, BAS1-chloroplastic-like, probable glutathione s-transferase, mannose- 6-phosphate isomerase 1-like) were significantly higher in jail, whereas an oxidase protein (monooxygenase 1 ) was decreased in jail compared to WT after TA treatment, suggesting that ROS may act downstream of COI1 to promote TA induced PCD process.

The levels of two ceramide synthesis related proteins, melibiase family protein and serine palmitoyltransferase, were higher in jail than in WT after TA treatment, indicating that COI1-dependent JA signaling might promote TA induced PCD by regulating the biosynthesis of ceramide. Proteins related to autophagy, which plays a role in maintaining the intracellular homeostasis, were also found among the list of DE proteins. Autophagy-related protein 11 (ATG 11) was decreased in jai1, whereas RIBONUCLEASE 2-LIKE as a negative regulator of autophagy, was increased in jail after TA treatment. The results indicated that autophagy might be promoted by COI1-dependent JA signaling, and related to inhibition of TA induced PCD. Kunitz Trypsin Inhibitor (KTI1) was previously proved to be an antagonist of cell death triggered by phytopathogens and Fumonisin B1 in Arabidopsis $^{28}$. In the current survey, it was increased in jail by two folds. Metacaspase type II and the peptidase C14 caspase catalytic subunit P20, as potential PCD regulators, were increased slightly in jai1. This result was different from the former report that the type-II metacaspase from tomato (LeMCA1) was not increased during chemical induced PCD in suspension-cultured tomato cells ${ }^{29}$. As tomato genome contains at least two type-II metacaspases, we speculate that different metacaspases might have distinct functions during PCD process, and display different expression patterns. Most of the above results partly explained why PCD was lighter in jail than in WT.

Our previous studies have shown that JA, ET and SA are involved in the response of tomato leaves to AAL or AAL toxin ${ }^{30}$. In the current survey, we paid more attention to the proteins relevant to these three hormone pathways. The expression of two JA biosynthetic genes, 12-oxophytodienoate reductase 3 and allene oxide synthase were increased in jail, while some of the JA response genes were decreased, due to the impaired perception of JA. ET biosynthesis and response were inhibited, whereas SA synthesis and response were enhanced in jail mutant, suggesting that COI1-dependent JA signaling acts synergistically with ET, and antagonistically with SA during response to TA. Several proteins in ABA response pathway, were decreased in jail after TA treatment (Table 3), indicating that COI1-dependent JA signaling might interact with ABA pathway in regulating TA induced PCD. 


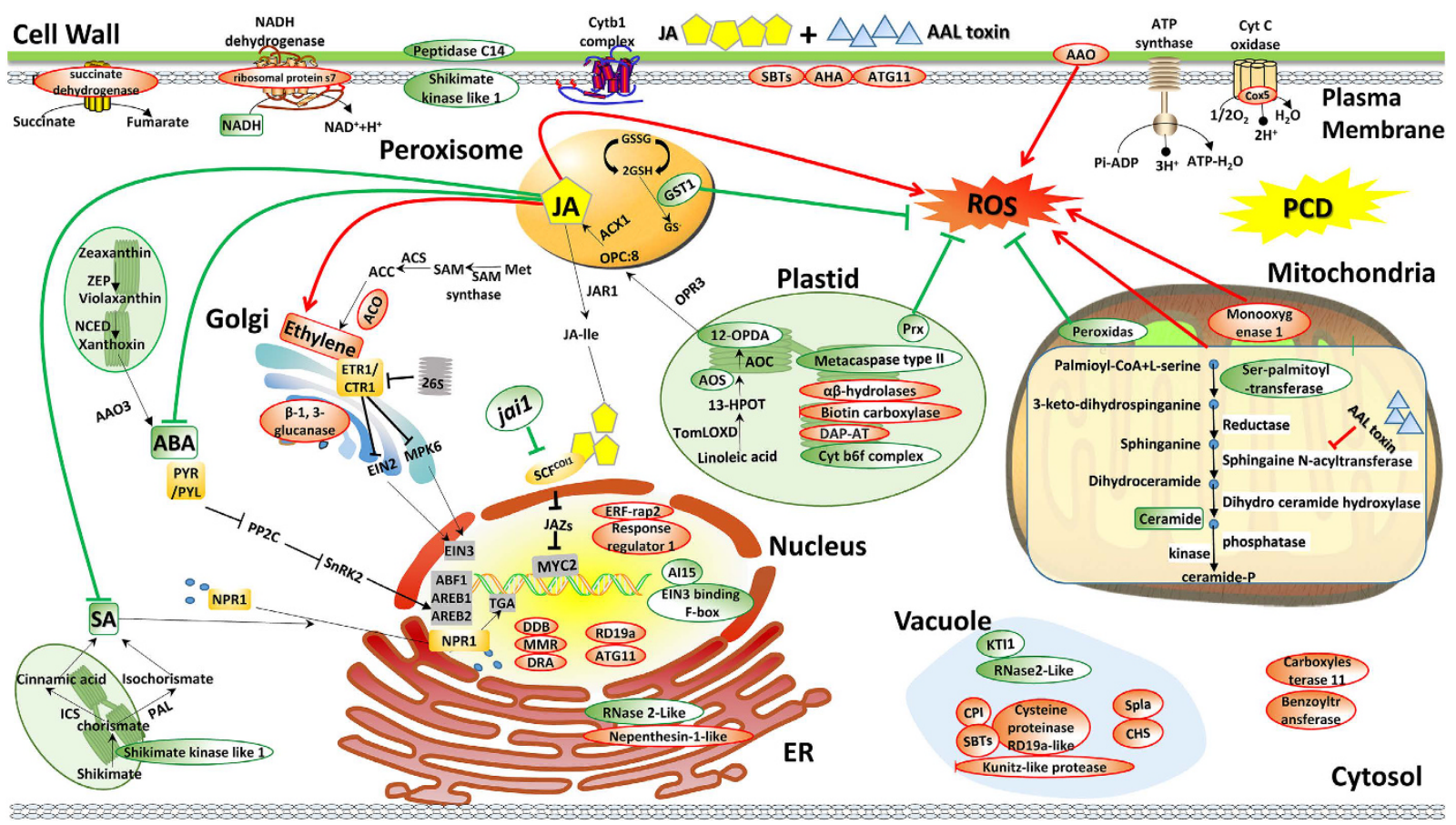

Figure 4. A putative model showing possible mechanisms of JA regulated AAL toxin response in Solanum Lycopersicum. The DE proteins caused by JA treatment and COI1 mutation during AAL toxin induced PCD were used to construct the model, and the impairment of COI1 induced protein changes were presented with the contrary change patterns. The identified proteins were assigned to different organelles or groups according to their subcellular localization and molecular functions. Up-regulated proteins are highlighted red and down-regulated proteins are colored green. Arrows and bars represent positive and negative regulation respectively. Red solid lines indicate that the pathways are up-regulated or promoted by JA during TA response, green solid lines with bars or arrows indicate that the pathways are down-regulated by JA during TA response, black solid lines with arrows links the proteins within the same pathway. TA induce PCD by inhibiting the synthesis of ceramide and inducing the overproduction of ROS, COI1-dependent JA pathway may promote this PCD progress by influencing the ROS production and scavenging, other hormone signaling pathways or some possible PCD regulators such as caspase-like proteins, autophagy and DNA repair related proteins. AAO, L-ascorbic acid oxidase; ABI1, ABA insensitive1; ACO1, 1-aminocyclopropane-1-carboxylate oxidase homolog 1-like; AHA, plasma membrane $\mathrm{H}^{+}$-ATPase; AOS, allene oxide synthase; ATG11, autophagy related protein 11; CHS, chalcone synthase; CPI, cysteine protease inhibitor; Cyt, Cytochrome; DAP-AT, probable n-succinyldiaminopimelate aminotransferase-like; DDB, DNA damage binding proteins; DDR, DNA damage response; DRA, DNA repair ATPase-related family protein; ER, endoplasmic reticulum; GST, glutathione S-transferase; Golgi, golgi complex; KTI1, kunitz trypsin inhibitor; MMR, DNA mismatch repair; NAT, nucleobase-ascorbate transporter 6-like; Prx, Peroxiredoxin; RNase E, Ribonuclase 2-Like; SBTs, subtilisin-like proteases; TF, transcription factor.

\section{Discussion}

Previous studies have shown that AAL toxin can inhibit ceramide biosynthetic enzymes and lead to PCD in sensitive asc/asc tomato species, due to the reduced sphingolipids and accumulated dihydrosphingosine (DHS) and 3-ketodihydrosphingosine (3-KDHS) ${ }^{31,32}$. However, the underlying mechanism from toxin perception to PCD process is poorly understood in plants. Our research explored the potential pathways and regulators in AAL toxin induced PCD and the role of COI1-dependent JA signaling pathway in regulating the PCD process.

Proteases specifically the classical proteolytic enzymes called caspases, were reported to be participated in the regulation of animal $\mathrm{PCD}$, implies that proteases may be involved in regulation of plant $\mathrm{PCD}^{33}$. Several reports also have proved the involvement of proteases in regulating plant PCD. Both protease activity and cell death were inhibited by soybean trypsin inhibitor, while exogenous application of another serine protease prematurely triggered cell death ${ }^{34}$. In tobacco, inhibition of the induced cysteine protease activity by ectopic expression of a cysteine protease inhibitor (CPI) gene, blocked the PCD triggered either by an avirulent pathogen or by $\mathrm{ROS}^{26}$. We identified several JA treatment induced proteases during AAL toxin induced PCD, including a kunitz-like protease, a cysteine proteinase RD19a-like, an aspartic proteinase nepenthesin-1-like. a $\beta$-1, 3-glucanase and four SBT or SBT like proteins (Table 2). Moreover, we also found that CPI was increased by two fold after toxin treatment alone, while it was increased by 23 fold after TA and JA treatment. The results suggest that TA treatment promoted the expression of some specific proteases to induce PCD, and JA treatment enhanced the response. However, two other caspase-like proteases, metacaspase type II and the peptidase C14 caspase catalytic subunit P20, were increased slightly in jail and decreased in WT after TA treatment, suggesting that these two proteases 
may function as negative regulators of plant PCD. Kunitz trypsin inhibitor gene (KTI1) was proved to play a regulatory role in PCD antagonizing pathogen and Fumonisin B1 induced cell death ${ }^{28}$. The KTI1 found in our study was increased in jail by two folds in comparison with WT after TA treatment (Table 3), implying that KTI1 is also a negative regulator of plant PCD induced by TA.

Mitochondrial quality control is important in maintaining proper cellular homeostasis, and selective mitochondrial degradation by autophagy (mitophagy) is suggested to play an important role in quality control ${ }^{34}$. Selective autophagy includes the cytoplasm to vacuole targeting (Cvt) pathway ${ }^{35}$ and pexophagy ${ }^{36}$. To date, 31 autophagy-related genes have been identified, which function as the molecular machinery for autophagy. Among them, ATG 11 is essential for mitophagy, acting as an adaptor protein that is needed along with ATG 19 to recruit the Cvt complex to phagophore assembly site (PAS), where the sequestering cytosolic vesicles are generated ${ }^{37}$. In the present study, ATG 11 in tomato was was found to be decreased by COI1 impairment after AAL toxin treatment. Conversely, the autophagy negative regulator RIBONUCLEASE 2-LIKE was significantly increased by COI1 impairment during AAL toxin induced PCD, suggesting that autophagy in jail was suppressed, leading to reduced cell death.

In addition to the putative PCD regulators conserved throughout animal and plant, there also exist some plant-specific mediators of PCD. Various plant hormones are strong candidates, and supporting evidence began to accumulate ${ }^{38}$. Our previous studies showed that COI1-dependent JA pathway acts upstream of ET to promote TA-triggered $\mathrm{PCD}^{11}$, which was further verified by the proteomic evidence in this study. The modulator of AAL cell death 1 (MACD1), which is an AP2/ERF transcription factor acting downstream of ET signaling, has been reported to positively regulate AAL triggered cell death ${ }^{29}$. We found that an AP2/ERF transcription factor RAP27-like was decreased significantly in jail during response to TA, suggesting that COI1-mediated JA signaling promote TA induced PCD by enhancement of ET response via RAP2-7 like. The resistance of tomato plants to AAL and AAL toxin is enhanced by SA pathway ${ }^{30}$. The proteins related to SA biosynthesis and response were increased in jail mutant after TA treatment, indicating that COI1-dependent JA pathway interacts with SA pathway in an antagonistic way to enhance TA induced PCD.

ROS have emerged as important signals in activation of plant PCD. Studies on exogenous application of $\mathrm{H}_{2} \mathrm{O}_{2}$ confirmed the role of $\mathrm{H}_{2} \mathrm{O}_{2}$ as a cell death trigger ${ }^{39}$. $\mathrm{Zhang}^{40}$ also proved that AAL toxin induced PCD is closely related to the production of ROS. In the present study, the decreased levels of $\mathrm{H}_{2} \mathrm{O}_{2}$ and $\mathrm{O}_{2}{ }^{-{ }^{-}}$in jail is consistent with the reduced cell death in jail after AAL toxin treatment, suggesting that JA exert its effects on plant PCD through regulation of ROS accumulation. Inhibitors of ET biosynthesis or perception blocked $\mathrm{H}_{2} \mathrm{O}_{2}$ production and cell death in tomato suspension cells ${ }^{41}$, therefore the decreased ROS production in jail might be owing to the inhibited ET pathway. In addition, JA also acted through regulation of ET pathway in many cases, for example, JA-promoted lycopene was correlated with JA-stimulated ET production ${ }^{42}$, and both ET biosynthesis and the signaling pathway are strongly decreased in jail leaves inoculated with AAL when compared with $\mathrm{WT}^{30}$. The Arabidopsis jasmonate-insensitive mutant jarl shows enhanced cell death after exposure to $\mathrm{O}^{3-}$, and wounding or treatment with JA has been shown to reduce $\mathrm{O}^{3-}$ induced cell death and ROS levels ${ }^{16}$, in contrast to our finding in TA induced PCD. Complex mechanisms exist among PCD processes induced by distinct factors, which may be species-specific. Besides JA and ET, ABA seems to act downstream of COI1-mediated JA signaling in promoting TA induced PCD. Virus induced gene silencing (VIGS) analyses proved that AAL toxin triggered cell death is dependent on the mitogen-activated protein kinase MEK2 in tobacco ${ }^{43}$. We observed that the mitogen-activated protein kinase 9-like (MAPK9-Like) was significantly decreased in jail after TA treatment, suggesting a possible role of MAPK9-Like in response to TA in tomato leaves.

The CCR4-NOT transcription complex has been well known as mRNA deadenylases in eukaryotic cells. Liang et al. ${ }^{44}$ proved that the homologs of CCR4-associated factor 1 (CAF1) in Arabidopsis are involved in defence responses to pathogen infections. In our results, two subunits of CCR4-NOT transcription complex were upregulated in jail mutant compared with the wild type (Supplementary Table S4), indicating that the CCR4-NOT transcription complex is also involved in the defence responses to AAL toxin in tomato.

In plants, plasma membrane $(\mathrm{PM}) \mathrm{H}^{+}$-ATPases are the primary pumps responsible for the establishment of cellular membrane potential, which are absolutely essential for normal plant growth and development ${ }^{45}$. A PM $\mathrm{H}^{+}$-ATPase was slightly decreased by TA treatment, suggesting its function in toxin response. Moreover, if DNA damage is left unrepaired or mis-repaired, it can be changed into a mutation. Three DNA damage response related proteins were found to be increased by JA, indicating that JA promotes the DNA repair process to cope with the occurrence of the PCD and mutation.

In summary, we explored the mechanisms in JA regulation of AAL toxin induced PCD using comparative proteomics. We identified a large number of DE proteins induced by TA + JA treatment in WT and jail. The DE proteins revealed by iTRAQ quantitative proteomics approach in this study help to elucidate the molecular regulating network of COI1-dependent JA pathway in PCD. Numerous new components in cell death machinery were identified, which were summarized in several pathways and represented in Fig. 4. TA causes PCD by inhibiting the synthesis of ceramide and inducing the overproduction of ROS. COI1-dependent JA pathway may promote this PCD progress by influencing the ROS production and scavenging, other hormone signaling pathways or some possible PCD regulators such as caspase-like proteins, autophagy and DNA repair related proteins. Our findings have deepened the understanding of the mechanisms in fungal toxin induced PCD and JA mediated plant defense in response to the fungal toxin. Many of the proteins identified in the present study including their modifications are interesting targets for further genetic and molecular studies to establish the precise roles in cell death and defense regulatory networks.

\section{Methods}

Plant growth and selection of jai1 homozygotes. Tomato (S. lycopersicum) cultivar Castlemart (CA) is the parental line for JA insensitive mutant jail. Seeds were germinated on the filter paper after 
treatment with $1 \%$ sodium hypochlorite $(\mathrm{NaOCl})$ for 10 minutes. The germinated seedlings were treated with $1 \mathrm{mM}$ MeJA (Sigma, St Louis, MO, USA). Approximately $24 \mathrm{~h}$ or $36 \mathrm{~h}$ later, MeJA-insensitive seedlings (roots growth is not inhibited by MeJA) were selected by PCR using genomic DNA using three primers below: P1: 5'-GTGGAGACGATATGTTGAGACTAA-3'; P2: 5'-CCATGGAG TCCATCACCTAACAGT-3'; P3: 5'-GTGGTCAGATCAGAGCCCTCTATT-3'; PCR product with only a 777 bp band are homozygous jail mutant. Seedlings were grown in the growth chamber with day/night temperature of $26 / 18^{\circ} \mathrm{C}(16 / 8 \mathrm{~h})$. All experiments were carried out using fully expanded leaflets from nodes 4-6 (except for the terminal leaflets) of 7-week-old tomato plants. jail homozygotes were screened according to Li et al. ${ }^{14}$.

Detached leaflet treatment with JA and AAL Toxin. Treatment was performed as described earlier ${ }^{46,47}$. The treatment solutions contained different concentrations of JA $(0,10,100$, or $500 \mu \mathrm{M})$ and $0.2 \mu \mathrm{M}$ TA (the most common kind of AAL toxin ${ }^{8}$ ) under continuous light at $25^{\circ} \mathrm{C}$, sodium phosphate buffer (SPB, pH 7.0) was used as a control. Four excised leaflets from individual plants were incubated for different time periods on a piece of filter paper in one Petri dish.

Cell death assays. Cell death was detected using trypan blue staining. Detached leaves were submerged in the farmers solution (acetic acid:ethanol:chloroform $=1: 6: 3, \mathrm{~V} / \mathrm{V} / \mathrm{V}$ ) to make it transparent, dyed in the solution involving $0.05 \% \mathrm{w} / \mathrm{v}$ trypan blue and ethanol $(1: 2 \mathrm{~V} / \mathrm{V})$, and then washed with water and decolorized in saturated chloral hydrate.

Detection of malondialdehyde content. Leaf samples $(0.4 \mathrm{~g}$ each $)$ were ground in $4 \mathrm{~mL}$ of phosphate buffer (0.05 M PBS, pH 7.8, $0.2 \mathrm{mM}$ EDTA, 2\% polyvinyl pyrrolidone), centrifuged at $12000 \mathrm{~g}$ for $20 \mathrm{~min}$ and the total supernatant was used for the measurement. The measurement of malondialdehyde (MDA) content was calculated from the thiobarbituricacid (TBA) reaction using an extinction coefficient of $155 \mathrm{mM}^{-1} \mathrm{~cm}^{-148}$. One milliliter supernatant was added into $3 \mathrm{~mL}$ of TBA solution, kept at $95^{\circ} \mathrm{C}$ for $30 \mathrm{~min}$, centrifuged at $1500 \mathrm{~g}$ for $10 \mathrm{~min}$, and then MDA content was calculated according to the absorbance measured at $600 \mathrm{~nm}, 532 \mathrm{~nm}$, and $450 \mathrm{~nm}$, respectively.

Detection and quantification of $\mathrm{H}_{2} \mathrm{O}_{2}$ and superoxide. Intracellular $\mathrm{H}_{2} \mathrm{O}_{2}$ was detected by 3 , $3^{\prime}$-diaminobenzidine tetrahydrochloride $(\mathrm{DAB})$ staining, showing a brown stain caused by the polymerization of $\mathrm{DAB}^{21}$. Superoxide $\left(\mathrm{O}_{2} \cdot{ }^{-}\right)$was detected by staining leaves with nitro bluetetrazolium chloride (NBT), which is reduced by superoxide to form a dark blue, water-insoluble formazan ${ }^{22}$. The $\mathrm{O}_{2}{ }^{-}$production rate was measured by analyzing the nitrite formation from hydroxylamine in the presence of $\mathrm{O}_{2}{ }^{-}{ }^{-}$. Frozen leaf segment was homogenized with $3 \mathrm{~mL}$ of $65 \mathrm{mM}$ Phosphate Buffered Saline (PBS, pH 7.8) and centrifuged at $5000 \mathrm{~g}$ for $10 \mathrm{~min}$. After incubation in the solution containing $0.9 \mathrm{~mL}$ of $65 \mathrm{mM}$ PBS (pH 7.8), $0.1 \mathrm{~mL}$ of $10 \mathrm{mM}$ hydroxylamine hydrochloride, and $1 \mathrm{~mL}$ of the supernatant at $25^{\circ} \mathrm{C}$ for $20 \mathrm{~min}, 17 \mathrm{mM}$ sulphanilamide and $7 \mathrm{mM}$ anaphthylamine were added. Ethylether in the same volume was added and centrifuged at $1500 \mathrm{~g}$ for $5 \mathrm{~min}$. The absorbance in the aqueous solution was monitored at $530 \mathrm{~nm}^{49}$. Quantification of $\mathrm{H}_{2} \mathrm{O}_{2}$ was done as follows: $0.4 \mathrm{~g}$ samples were ground in cold acetone and centrifuged at $3000 \mathrm{~g}$ for $10 \mathrm{~min}$, the supernatant was then mixed with $0.2 \mathrm{~mL}$ of $20 \%$ $\mathrm{TiCl}_{4}$ and $0.4 \mathrm{~mL}$ of ammoni, the precipitation was washed with acetone for five times, finally dissolved in $3 \mathrm{~mL}$ of $2 \mathrm{M} \mathrm{H}_{2} \mathrm{SO}_{4}$, and determined spectra-photometrically by measuring the absorbance at $595 \mathrm{~nm}$.

Protein extraction and quantification. Proteins from tomato leaves of four biological replicates were prepared according to Hurkman and Tanaka ${ }^{50}$ with the following modifications. Samples were ground in liquid nitrogen into fine powder and incubated in extraction buffer $(0.1 \mathrm{M}$ Tris- $\mathrm{HCl} \mathrm{pH} \mathrm{8.8,} 10 \mathrm{mM}$ EDTA, $0.2 \mathrm{M}$ DL-Dithiothreitol, $0.9 \mathrm{M}$ sucrose), continued by grinding in a fume hood, and then the extract was agitated for $2 \mathrm{hrs}$ at room temp. After washing twice with $0.1 \mathrm{M}$ ammonium acetate in methanol and twice with $80 \%$ acetone, the dried pellet was dissolved with 2D buffer (8 M Urea, 4\% CHAPS, $40 \mathrm{mM}$ Tris-base, $2 \mathrm{M}$ Thiourea). Protein assays were performed using an EZQ Protein Quantitation Kit (Invitrogen, Carlsbad, CA, USA) with the SoftMax Pro Software v5.3 (Molecular Devices, Downingtown, PA, USA).

Protein precipitation, ITRAQ labeling, strong cation exchange, LC-MS/MS. For each sample, $50 \mu \mathrm{g}$ protein was dissolved in the dissolution buffer with $1 \mu \mathrm{l}$ of denaturant in the iTRAQ reagents 8-plex kit (AB Sciex, Inc., Foster City, CA, USA). The samples were reduced with Tris (2-Carboxyethyl) Phosphine (TCEP), alkylated with methyl methanethiosulfonate (MMTS), trypsin-digested, and labeled according to the manufacturer's instructions for the iTRAQ reagents 8-plex kit (AB Sciex Inc., California, USA). Mock lines (wild type, CA) were labeled with iTRAQ tags 113 and 117; TA treated WT lines were labeled with tags 114 and 118; TA and jasmonic acid treated WT lines were labeled with tags 115 and 119; TA treated jail lines were labeled with tags 116 and 121. The biological quadruplicates were analyzed to account for variation among individuals. The combined peptide mixtures were desalted and lyophilized. After labeling, samples were combined, desalted with solid phase extration (The Nest Group, Inc., Southborough, MA, USA), lyophilized and dissolved in strong cation exchange (SCX) solvent A (25\% (v/v) acetonitrile, $10 \mathrm{mM}$ ammonium formate and $0.1 \%(\mathrm{v} / \mathrm{v})$ formic acid ( $\mathrm{pH} 2.8))$. The peptides were fractionated using an Agilent HPLC system 1260 with a polysulfoethyl column $(2.1 \mathrm{~mm} \times 100 \mathrm{~mm}$, $5 \mu \mathrm{L}, 300 \AA$ A; PolyLC, Columbia, MD, USA), flow rate of $0.2 \mathrm{~mL} / \mathrm{min}$. Peptides were eluted with a linear gradient of $0-20 \%$ solvent B ( $25 \%$ (v/v) acetonitrile and $500 \mathrm{mM}$ ammonium formate ( $\mathrm{pH} 6.8)$ ) over $50 \mathrm{~min}$, followed by ramping up to $100 \%$ solvent $\mathrm{B}$ in $5 \mathrm{~min}$. The absorbance at $280 \mathrm{~nm}$ was monitored; 12 fractions were collected and lyophilized. The fractions were resuspended in LC solvent A ( $0.1 \%$ formic acid in $97 \%$ water, $3 \%$ acetonitrile). A hybrid quadrupole Orbitrap (Q Exactive) MS system (Thermo Fisher Scientific, Bremen, Germany) was used with high energy collisional dissociation (HCD) after each MS. The instrument was run in data dependent mode 
with a full MS (400-2000 m/z) resolution of 70,000 and five $\mathrm{ms} / \mathrm{ms}$ ( 17500 resolution, HCD NCE $=28 \%$, isolation width $=3 \mathrm{Th}$, first mass $=105 \mathrm{Th}$., $5 \%$ underfill ratio, peptide match set to 'preferred', and an AGC target of $1 \mathrm{e}^{6}$ ). Dynamic exclusion of $10 \mathrm{~s}$ was applied to prevent repeated analyses of the same peptides, and a lock mass of $\mathrm{m} / \mathrm{z}$ 445.12003 (polysiloxane ion) was used for real-time internal calibration.). The MS system was interfaced with an automated Easy-nLC 1000 system (Thermo Fisher Scientific, Germerling, Germany). Each sample fraction was loaded on an Acclaim Pepmap 100 pre-column $(20 \mathrm{~cm} \times 75 \mu \mathrm{m} ; 3 \mu \mathrm{m}-\mathrm{C} 18)$ and separated using a PepMap RSLC analytical column $(250 \mathrm{~cm} \times 75 \mu \mathrm{m} ; 2 \mu \mathrm{m}-\mathrm{C} 18)$ with a flow rate at $350 \mathrm{nl} / \mathrm{min}$. A linear gradient of solvent A $(0.1 \%$ formic acid) to solvent B ( $0.1 \%$ formic acid, $99.9 \%$ acetonitrile) was run for $95 \mathrm{~min}$, followed by a ramp to $98 \%$ B for $5 \mathrm{~min}$. The MS proteomics data have been deposited in the ProteomeXchange Consortium ${ }^{51}$ via the PRIDE partner repository with the data set identifier PXD002864 and 10.6019/PXD002864.

ITRAQ LC-MS/MS data analysis. The raw MS/MS data files were searched against the specified non-redundant database (combined Uniprot, http://www.uniprot.org/uniprot/?query = solanum +lycopersicum\&sort = score; NCBI, http://www.ncbi.nlm.nih.gov/gquery/?term=solanum+lycopersicum; Phytozome, http://www.phytozome.net/tomato.php) using the Fraglet and Taglet searches under the Paragon ${ }^{\mathrm{TM}}$ algorithm ${ }^{52}$ of ProteinPilot v.4.5 software (AB Sciex, Inc.). Plant species, fixed modification of methylmethane thiosulfate-labeled cysteine, fixed iTRAQ modification of amine groups in the N-terminus and lysine, and variable iTRAQ modifications of tyrosine were considered. In addition, the iTRAQ data were analyzed using Proteome Discoverer v1.4 (Thermo Fisher Scientific, Bremen, Germany) and the following parameters: peptide tolerance at $10 \mathrm{ppm}$, tandem MS tolerance at $\pm 0.01 \mathrm{Da}$, peptide charges of $2+$ to $5+$, trypsin as the enzyme, allowing one missed cleavage, iTRAQ label and methyl methanethiosulfonate $(\mathrm{C})$ as fixed modifications, and oxidation (M) and phosphorylation (S, T, Y) as variable modifications. Peptides and proteins were filtered using ProteoIQ 2.7 (Premier Biosoft, Palo Alto, CA, USA) with strict peptide and protein probabilities, 0.8 and 0.95 , respectively. For peptide confidence, we adopted the following cutoff values of Xcorr that are commonly used for the SEQUEST algorithm ${ }^{53}: 2.31$ for $2+, 2.41$ for $3+$, and 2.6 for $4+$ peptides $^{54}$. Peptide probability was applied to filter peptide assignments obtained from MS/MS database searching results using predictable false identification error rate (See Supplementary Table S2 for peptide information). To be differentially expressed with significance, a protein must have been quantified with a fold change $>1.2$ or $<0.8$, with at least three spectra in at least two of the biological quadruplicates, along with a Fisher's combined probability $<0.05^{55}$. A protein is considered to be variable if it has an increase in expression in one component of the comparison and a decrease in the other; these variable proteins within biological replicates were excluded for further analysis. Functional analyses of proteins in biological process, molecular function, and cellular component were conducted using GO annotation (http://www.geneontology.org/) with Fisher's exact test based on false discovery rate $(p \text {-value } \leq 0.05)^{56}$. Blast2GO level $2-11$ filtering was used to examine unique protein changes during comparison analysis. Accession numbers were compared between each genotype and treatment, and unique proteins were identified.

Statistical analysis. Differences in the MDA content, $\mathrm{H}_{2} \mathrm{O}_{2}$ content and $\mathrm{O}_{2}{ }^{-}$- production rate were analyzed by one-way analysis of variance (ANOVA); if the ANOVA analysis was significant $(\mathrm{P}<0.05)$, Duncan's multiple range test was used to detect significant differences between groups.

\section{References}

1. Tsuge, T. et al. Host-selective toxins produced by the plant pathogenic fungus Alternaria alternata. FEMS Microbiol. Rev. 37, 44-66 (2013).

2. Brandwagt, B. F., Kneppers, T. J., Nijkamp, H. J. \& Hille, J. Overexpression of the tomato Asc-1 gene mediates high insensitivity to AAL toxins and fumonisin B1 in tomato hairy roots and confers resistance to Alternaria alternata f. sp. lycopersici in Nicotiana umbratica plants. Mol Plant Microbe Interact. 15, 35-42 (2002).

3. Grogan, R., Kimble, K. \& Misaghi, I. A stem canker disease of tomato caused by Alternaria alternata f. sp. lycopersici [Fungus diseases]. Phytopathol. 65 (1975).

4. Clouse, S. D. \& Gilchrist, D. G. Interaction of the asc locus in F8 paired lines of tomato with Alternaria alternata f. sp. lycopersici and AAL-toxin. Phytopathol. 77, 80-82 (1987).

5. Du, L. et al. Biosynthesis of sphinganine-analog mycotoxins. J Ind Microbiol. 35, 455-464 (2008).

6. Abbas, H. K. et al. Fumonisin-and AAL-toxin-induced disruption of sphingolipid metabolism with accumulation of free sphingoid bases. Plant Physiol. 106, 1085-1093 (1994).

7. Riley, R. T., Norred, W. P. \& Bacon, C. W. Fungal toxins in foods: recent concerns. Annu. Rev. Nutr. 13, 167-189 (1993).

8. Xu, L. \& Du, L. Direct detection and quantification of Alternaria alternata lycopersici toxins using high-performance liquid chromatography-evaporative light-scattering detection. J Microbiol Methods. 64, 398-405 (2006).

9. Tsuda, K., Sato, M., Stoddard, T., Glazebrook, J. \& Katagiri, F. Network properties of robust immunity in plants. PLoS Genet. 5, 61-82 (2009).

10. Glazebrook, J. Contrasting mechanisms of defense against biotrophic and necrotrophic pathogens. Annu Rev Phytopathol. 43, 205-227 (2005)

11. Zhang, L. et al. The involvement of jasmonates and ethylene in Alternaria alternata f. sp. lycopersici toxin-induced tomato cell death. J. Exp. Bot. 62, 5405-5418 (2011).

12. Gadjev, I. Z., Hille, J. \& Gechev, T. S. An extensive microarray analysis of AAL-toxin-induced cell death in Arabidopsis thaliana brings new insights into the complexity of programmed cell death in plants. Cell. Mol. Life Sci. 61, 1185-1197 (2004).

13. Egusa, M., Ozawa, R., Takabayashi, J., Otani, H. \& Kodama, M. The jasmonate signaling pathway in tomato regulates susceptibility to a toxin-dependent necrotrophic pathogen. Planta 229, 965-976 (2009).

14. Li, L. et al. The tomato homolog of CORONATINE-INSENSITIVE1 is required for the maternal control of seed maturation, jasmonate-signaled defense responses, and glandular trichome development. Plant cell 16, 126-143 (2004).

15. Dat, J. F. et al. Changes in hydrogen peroxide homeostasis trigger an active cell death process in tobacco. Plant J. 33, 621-632 (2003).

16. Rao, M. V., Lee, H., Creelman, R. A., Mullet, J. E. \& Davis, K. R. Jasmonic acid signaling modulates ozone-induced hypersensitive cell death. Plant cell 12, 1633-1646 (2000).

17. Zhang, A., Xu, T., Zou, H. \& Pang, Q. Comparative proteomic analysis provides insight into cadmium stress responses in brown algae Sargassum fusiforme. Aquat Toxicol. 163, 1-15 (2015). 
18. Dai, S. J., Pang, Q. Y., Tian, Y. X., Chen, S. X. \& Yan, X. F. Proteomic Analysis of Arabidopsis Leaves Subjected to Mechanical Wounding. Curr. Proteomics 12, 124-136 (2015).

19. Tennant, J. R. Evaluation of the trypan blue technique for determination of cell viability. Transplantation 2, 685-694 (1964).

20. Davey, M. W., Stals, E., Panis, B., Keulemans, J. \& Swennen, R. L. High-throughput determination of malondialdehyde in plant tissues. Anal Biochem 347, 201-207 (2005).

21. Torres, M. A., Dangl, J. L. \& Jones, J. D. Arabidopsis gp91phox homologues AtrbohD and AtrbohF are required for accumulation of reactive oxygen intermediates in the plant defense response. PNAS 99, 517-522 (2002).

22. Shinogi, T., Suzuki, T., Kurihara, T., Narusaka, Y. \& Park, P. Microscopic detection of reactive oxygen species generation in the compatible and incompatible interactions of Alternaria alternata Japanese pear pathotype and host plants. J Gen Plant Pathol. 69, 7-16 (2003).

23. Ogata, H. et al. KEGG: Kyoto Encyclopedia of Genes and Genomes. Nucleic Acids Res. 27, 29-34(26) (1999).

24. Shi, Y. Mechanisms of caspase activation and inhibition during apoptosis. Mol. Cell 12, 459-470 (2002).

25. Vartapetian, A. B., Tuzhikov, A. I., Chichkova, N. V., Taliansky, M. \& Wolpert, T. J. A plant alternative to animal caspases: subtilisinlike proteases. Cell Death Differ. 18, 1289-1297 (2011).

26. Solomon, M., Delledonne, M., Menachem, E., Levine, A. \& Belenghi, B. The involvement of cysteine proteases and protease inhibitor genes in the regulation of programmed cell death in plants. Plant cell 11, 431-443 (1999).

27. Czarny, P., Pawlowska, E., Bialkowska-Warzecha, J., Kaarniranta, K. \& Blasiak, J. Autophagy in DNA damage response. Int J Mol Sci. 16 (2015).

28. Li, J., Brader, G. \& Palva, E. T. Kunitz trypsin inhibitor: an antagonist of cell death triggered by phytopathogens and fumonisin B1 in Arabidopsis. Mol. Plant 1, 482-495 (2008).

29. Mase, K. et al. Ethylene-responsive AP2/ERF transcription factor MACD1 participates in phytotoxin-triggered programmed cell death. Mol Plant Microbe Interact. 26, 868-879 (2013).

30. Jia, C. et al. Multiple phytohormone signalling pathways modulate susceptibility of tomato plants to Alternaria alternata f. sp. lycopersici. J. Exp. Bot. 64, 637-650 (2013).

31. DV., L. Enzymes of sphingolipid metabolism in plants. Methods in Enzymol. 311, 130-149 (2000).

32. Wang, E., Norred, W. P., Bacon, C. W., Riley, R. T. \& A H Merrill, J. Inhibition of sphingolipid biosynthesis by fumonisins. Implications for diseases associated with Fusarium moniliforme. J Biol Chem. 266, 14486-14490 (1991).

33. Fuentes-Prior, P. \& Salvesen, G. S. The protein structures that shape caspase activity, specificity, activation and inhibition. Biochem. J. 384, 201-232 (2004).

34. Groover, A. \& Jones, A. M. Tracheary element differentiation uses a novel mechanism coordinating programmed cell death and secondary cell wall synthesis. Plant Physiol. 119, 375-384 (1999).

35. Klionsky, D. J. \& Emr, S. D. Autophagy as a regulated pathway of cellular degradation. Science 290, 1717-1721 (2000).

36. Dunn, J. et al. Pexophagy: the selective autophagy of peroxisomes. Autophagy 1, 75-83 (2005).

37. Shintani, T., Huang, W. P., Stromhaug, P. E. \& Klionsky, D. J. Mechanism of cargo selection in the cytoplasm to vacuole targeting pathway. Dev Cell 3, 825-837 (2002)

38. Hoeberichts, F. A. \& Woltering, E. J. Multiple mediators of plant programmed cell death: interplay of conserved cell death mechanisms and plant-specific regulators. Bioessays 25, 47-57 (2002).

39. Liang, H. et al. Ceramides modulate programmed cell death in plants. Genes Dev. 17, 2636-2641 (2003).

40. Zhang, L. Regulation of tomato responses to Alternaria alternata f. sp. lycopersici and AAL-toxin by plant hormones. Doctor Thesis, Zhejiang University (2011).

41. Jong, A. J. d., Yakimova, E. T., Kapchina, V. M. \& Woltering, E. J. A critical role for ethylene in hydrogen peroxide release during programmed cell death in tomato suspension cells. Planta 214, 537-545 (2002).

42. Liu, L. et al. Ethylene independent induction of lycopene biosynthesis in tomato fruits by jasmonates. J. Exp. Bot. 63, 5751-5761 (2012).

43. Mase, K. et al. Ethylene signaling pathway and MAPK cascades are required for AAL toxin-induced programmed cell death. Mol Plant Microbe Interact. 25, 1015-1025 (2012).

44. Liang, W. et al. The Arabidopsis homologs of CCR4-associated factor 1 show mRNA deadenylation activity and play a role in plant defence responses. Cell Res. 19, 307-316 (2009).

45. Elmore, J. M. \& Coaker, G. The role of the plasma membrane $\mathrm{H}^{+}$-ATPase in plant-microbe interactions. Mol Plant 4, 416-427 (2011).

46. Moore, T., Martineau, B., Bostock, R., Lincoln, J. \& Gilchrist, D. Molecular and genetic characterization of ethylene involvement in mycotoxin-induced plant cell death. Physiol Mol Plant Pathol. 54, 73-85 (1999).

47. Stefka, D. Spassievay, J. E. M. \& Jacques Hille. The plant disease resistance gene Asc-1 prevents disruption of sphingolipid metabolism during AAL-toxin-induced programmed cell death. Plant J. 32, 561-572 (2002).

48. Filippou, P., Antoniou, C. \& Fotopoulos, V. Effect of drought and rewatering on the cellular status and antioxidant response of Medicago truncatula plants. Plant Signal Behav. 6, 270-277 (2011).

49. Zhou, Y., Zhang, Y., Zhao, X., Yu, H. \& Shi, K., Yu, Jing. Impact of light variation on development of photoprotection, antioxidants, and nutritional value in Lactuca sativa L. J. Agric. Food Chem. 57, 5494-5500 (2009).

50. Hurkman, W. J. \& Tanaka, C. K. Solubilization of plant membrane proteins for analysis by two-dimensional gel electrophoresis. Plant Physiol. 81, 802-806 (1986).

51. Vizcaíno, J. A. et al. ProteomeXchange provides globally coordinated proteomics data submission and dissemination. Nat Biotechnol 32, 223-226 (2014).

52. Shilov, I. V. et al. The Paragon Algorithm, a next generation search engine that uses sequence temperature values and feature probabilities to identify peptides from tandem mass spectra. Mol Cell Proteomics. 6, 1638-1655 (2007).

53. Eng, J. K., McCormack, A. L. \& Yates, J. R. An approach to correlate tandem mass spectral data of peptides with amino acid sequences in a protein database. J Am Soc Mass Spectrom. 5, 976-989 (1994).

54. Jiang, X., Jiang, X., Han, G., Ye, M. \& Zou, H. Optimization of filtering criterion for SEQUEST database searching to improve proteome coverage in shotgun proteomics. BMC bioinformatics 8, 323 (2007).

55. Lury, D. A. \& Fisher, R. A. Statistical Methods For Research Workers, London. J R Stat Soc Ser C Appl Stat. 21 (1972).

56. Conesa, A. et al. Blast2GO: a universal tool for annotation, visualization and analysis in functional genomics research. Bioinformatics 21, 3674-3676 (2005).

\section{Acknowledgements}

TA was a gift from Dr. Liangcheng Du (Department of Chemistry, University of Nebraska, Lincoln, NE, USA). This work was supported by the Ministry of Agriculture of China (2014ZX08009-003-001), Zhejiang Provincial Natural Science Foundation of China (LZ15C150001), and National Science Foundation of China (31171951, 30970244). 


\section{Author Contributions}

Q.W. and S.C. designed the research. M.Z. and H.L. performed tomato plant growth and toxin treatment. M.Z. and Z.S. performed cell death assays. M.Z. and S.H. performed the detection of $\mathrm{H}_{2} \mathrm{O}_{2}$, superoxide and MDA content. L.L. and M.Z. performed protein extraction and quantification, as well as iTRAQ labeling. J.K., C.P.D. and N.Z. performed iTRAQ LC-MS/MS data analysis. M.Z. and Q.M. wrote the article.

\section{Additional Information}

Supplementary information accompanies this paper at http://www.nature.com/srep

Competing financial interests: The authors declare no competing financial interests.

How to cite this article: Zhang, M. et al. Critical Role of COI1-Dependent Jasmonate Pathway in AAL toxin induced PCD in Tomato Revealed by Comparative Proteomics. Sci. Rep. 6, 28451; doi: 10.1038/srep28451 (2016).

(c) (i) This work is licensed under a Creative Commons Attribution 4.0 International License. The images or other third party material in this article are included in the article's Creative Commons license, unless indicated otherwise in the credit line; if the material is not included under the Creative Commons license, users will need to obtain permission from the license holder to reproduce the material. To view a copy of this license, visit http://creativecommons.org/licenses/by/4.0/ 